\title{
$1 N-39$
}

NASA Technical Memorandum 106196

\section{Probabilistic Simulation of Multi-Scale} Composite Behavior

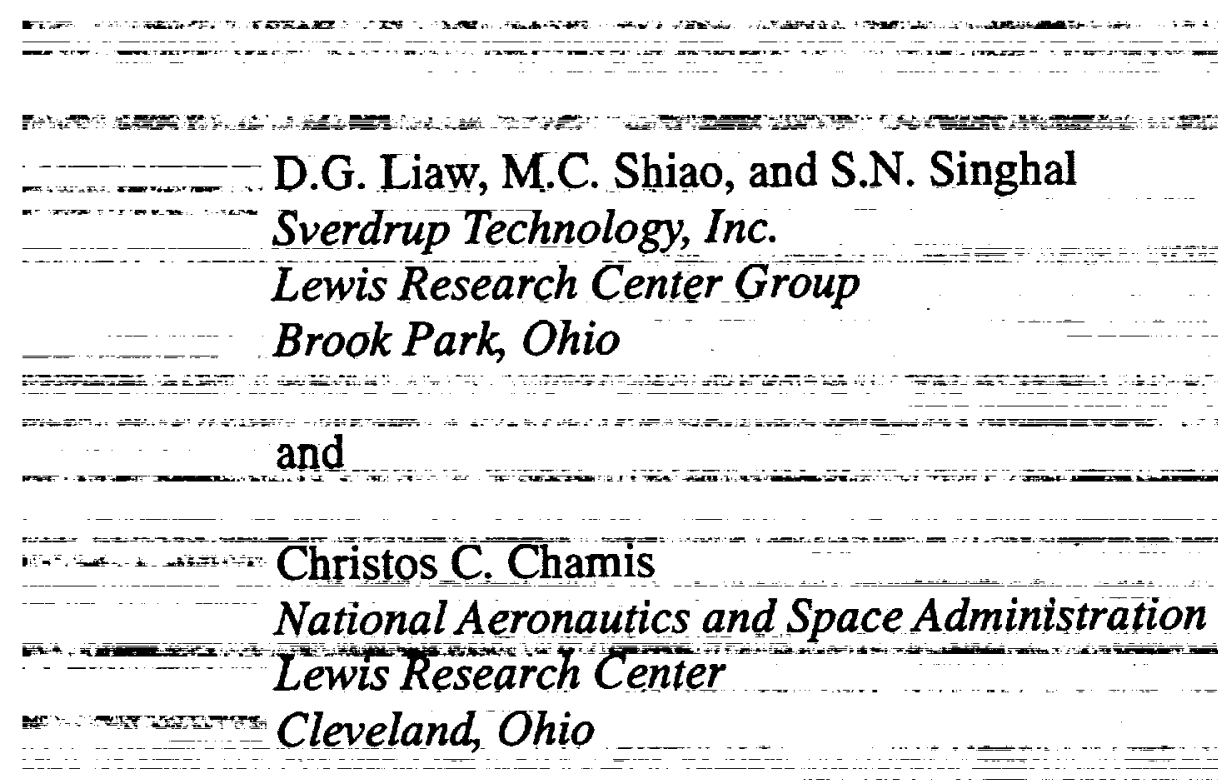

Prepared for the

Sixth Japan-United States Conference on Composite Materials

Orlando, Florida, June 22-25, 1992

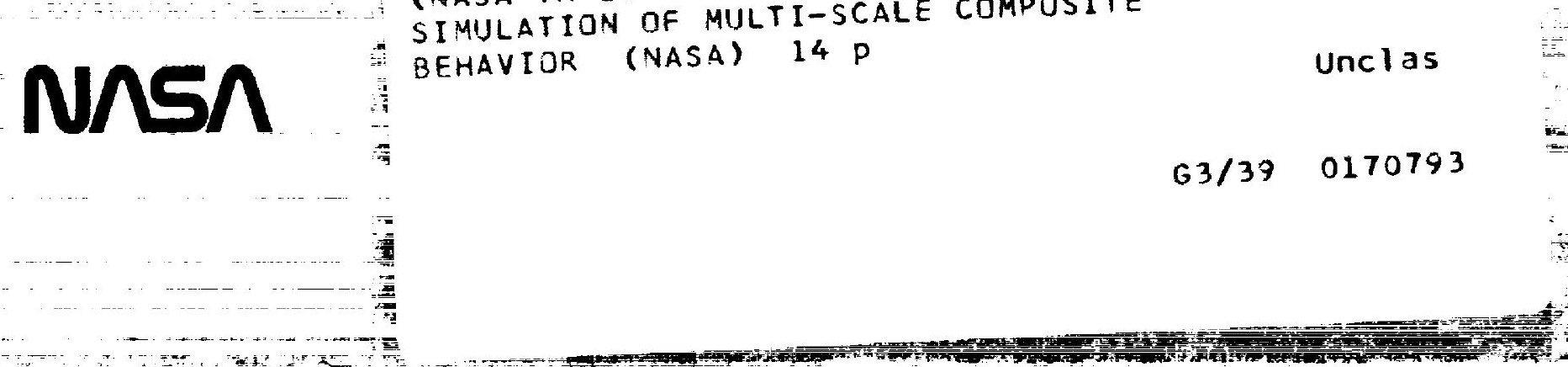





\title{
PROBABILISTIC SIMULATION OF MULTI-SCALE COMPOSITE BEHAVIOR
}

\author{
D.G. Liaw, M.C. Shiao, and S.N. Singhal \\ Sverdrup Technology, Inc. \\ Lewis Research Center Group \\ Brook Park, Ohio 44142
}

and

Christos C. Chamis

National Aeronautics and Space Administration

Lewis Research Center

Cleveland, Ohio 44135

\begin{abstract}
A methodology is developed to computationally assess the probabilistic composite material properties at all composite scale levels due to the uncertainties in the constituent (fiber and matrix) properties and in the fabrication process variables. The methodology is computationally efficient for simulating the probability distributions of material properties. The sensitivity of the probabilistic composite material property to each random variable is determined. This information can be used to reduce undesirable uncertainties in material properties at the macro scale of the composite by reducing the uncertainties in the most influential random variables at the micro scale. This methodology has been implemented into the computer code PICAN (Probabilistic Integrated Composite ANalyzer). The accuracy and efficiency of this methodology are demonstrated by simulating the uncertainties in the material properties of a typical laminate and comparing the results with the Monte Carlo simulation method. The experimental data of composite material properties at all scales fall within the scatters predicted by PICAN.
\end{abstract}




\section{INTRODUCTION}

Polymer matrix composites (PMC) form an important class of engineering materials in structural applications. Their outstanding mechanical properties, such as durability and corrosion-resistance characteristics, combined with low density are very attractive to the aerospace industry. The mechanical properties of composite materials depend on a wide variety of variables, for example: the fiber and matrix material properties; and fabrication variables at all stages of fabrication process, such as, fiber volume ratio, void volume ratio, fiber misalignment and ply thickness. These variables are statistical in nature, therefore, the mechanical properties of a composite material should be quantified probabilistically. As a consequence, the behavior of composite structures shows a scatter from its average value. Traditionally, an ad-hoc "safety factor" is used in the design to account for the difficulty in predicting the structural behavior. However, this approach may result in either an ultraconservative or an unsafe design.

In order to probabilistically assess the behavior of composite structures, a methodology was developed at the NASA Lewis Research Center for simulating the probabilistic material properties in all composite scales [1-3]. The methodology requires the identification of uncertainties at constituent and ply levels including material properties and fabrication variables. The random variables are then filtered through an analyzer which combines the composite mechanics and probability theory to computationally simulate the probabilistic material properties. Although the uncertainties in material properties can be computed by the Monte Carlo simulation (MCS) method, it is inefficient and expensive. In order to save computational time, the newly developed methodology uses the Fast Probability Integration (FPI) algorithm, instead of the traditional Monte Carlo simulation, to provide an efficient and affordable way for computationally simulating the uncertainties in composite material properties. The methodology was implemented in the computer code PICAN (Probabilistic Integrated Composite ANalyzer) (Ref. [4]) and is described in the present paper. The uncertainties of composite material properties at ply and laminate levels were simulated via PICAN. The sensitivity of a given material property to each random variable was also quantified.

\section{PROBABILISTIC SIMULATION OF COMPOSITE MATERIALS}

Composite materials are made of fiber and matrix through an appropriate fabrication process. Since the mechanical properties of the constituent material vary statistically, the uncertainties in composite material properties are produced from the uncertainties in the constituent material properties, also from the uncertainties in the fabrication parameters. The probabilistic simulation of composite material properties requires identification of uncertainties at all composite scales as described below.

Many thermoset laminated fiber-reinforced composite materials are manufactured by three basic steps: tape, layup and curing (see Fig. 1). The uncertainties incurred during the layup process are due to the misalignment of ply orientation. Typical uncertainties incurred 
from the curing process are intralaminate voids, incomplete curing of resin, excess resin between plies, excess matrix voids and porosity, and variation in ply thickness. Uncertainties incurred in the constituent material properties include all the fiber and matrix material properties. These uncertainties are referred to as the random variables (as enumerated in Figure 1) which will be processed computationally through composite mechanics and probability methods as depicted in Figure 2. The details of the computer code PICAN for the computational simulation of uncertainties in composite material properties are described next.

\section{PROBABILISTIC INTEGRATED COMPOSITE ANALYZER : PICAN}

PICAN (Probabilistic Integrated Composite ANalyzer) is a computer code for the probabilistic simulation of composite material properties. It integrates two NASA in-house computer programs, ICAN (Integrated Composite ANalyzer) (Ref. [5]) and FPI (Fast Probability Integrator) (Ref. [6]). ICAN was developed based upon composite mechanics to simulate the composite material behavior at all composite scales including many effects of environment and fabrication. FPI, developed using structural reliability algorithms, probabilistically processes the material property information generated by ICAN and efficiently computes the cumulative distribution functions (cdf) of composite material properties at all composite scales. Further details of ICAN and FPI are explained in the following.

\section{ICAN MODULE}

The ICAN module [5] performs a comprehensive analysis of composite material properties at all scales by selectively perturbing the random variables at the constituent level (fiber and matrix material properties, fiber volume ratio and void volume ratio), and the ply level (ply misalignment and ply thickness). Perturbed material properties at all composite scales corresponding to all the perturbed random variables are computed and stored in a database.

\section{FPI MODULE}

The FPI module [6] performs the probability calculations. It takes the relationship between the composite material property and the random variables as well as the probability distributions of the random variables to compute the probability distribution of that material property. The relationship is expressed as

$$
M_{p}=a_{0}+\sum_{i=1}^{N} a_{i} V_{i}+\sum_{i=1}^{N} b_{i} V_{i}^{2}
$$

where $\mathrm{M}_{\mathrm{p}}$ is any material property; $\mathrm{N}$ is the number of random variables considered; $\mathrm{V}_{\mathrm{i}}$ are the random variables; $a_{0}, a_{i}, b_{i}$ are calculated constants. More theoretical details concerning 
FPI can be found in Ref. [6].

\section{PICAN SIMULATION}

The random variables at the constituent and the ply levels are first identified and their respective distribution types and corresponding parameters are predetermined. These variables are then selectively perturbed in order to create a database to determine the constants $a_{0}, a_{i}$, and $b_{i}$ in the approximate relationship given by Eq. (1) between the composite material property and the random variables. For each set of perturbed values of random variables, composite micro-mechanics is used to determine the corresponding mechanical properties at the ply level. Laminate theory is then used to determine the corresponding mechanical properties at the laminate level. The process is repeated until enough data sets are generated by ICAN module that the functional relationship between material properties and random variables can be numerically determined through a least square curve fitting procedure in FPI module. For example, if each random variable is perturbed four times, a quadratic functional relationship can be obtained. With the known probabilistic distributions of the random variables and the numerically determined relationships between the composite material properties and the random variables, the fast probability integration is applied. For every discrete response value, a corresponding cumulative probability is computed by FPI. This process is repeated until the cumulative distribution function is represented with sufficient accuracy. The output information from FPI for a given material property includes its discretized cdf values, the coefficients for a special type of probability distribution function, and the sensitivities of the composite material property to the random variables.

\section{NUMERICAL RESULTS AND DISCUSSIONS}

The methodology described previously was applied to a 16-ply $\left(0_{2} / \pm 45 / 0_{2} / 90 / 0\right)_{\text {s }}$ graphite/epoxy (AS/3501-5) composite with $1.8 \%$ moisture at room temperature. The experimental data for the longitudinal modulus, transverse modulus, in-plane shear modulus, major Poisson's ratio, longitudinal and transverse tensile strengths, longitudinal and transverse compressive strengths, and in-plane shear strength of the graphite/epoxy unidirectional single ply and 16-ply composite laminate can be found in Ref. [7] and listed in Table 1. Based upon these experimental results (mean values) for the ply and laminate properties, the mean values of constituent material properties (fiber and matrix) were estimated. The assumed statistical properties (mean value, coefficient of variation (cov) or standard deviation (stdv), and distribution type) of each random variable are listed in Table 1. Typical probabilistic material properties for ply and laminate moduli and strengths were simulated. The sensitivities of the ply and laminate properties to the most sensitive random variables were also computed at two cumulative probability levels, 0.001 and 0.999 . All the cumulative distribution functions of the material properties at ply and laminate levels were compared with the results predicted by a Monte Carlo simulation with 1000 samples. Good agreement was observed. 
The cumulative distribution functions (cdf) of the ply moduli and the sensitivity information are shown in Figures 3 to 5. In each Figure, the experimental datum (mean value) is indicated by an arrow. In Figure 3, it is found that the ply modulus in the fiber direction $\left(E_{111}\right)$ is most sensitive to the fiber modulus and fiber volume ratio. This means that the reduction of the uncertainty in the ply modulus can be achieved mostly by the reduction of the uncertainties in the fiber modulus and fiber volume ratio. In Figure 4, it is found that the shear modulus of matrix and fiber volume ratio have the most contribution in the uncertainty of the ply in-plane shear modulus $\left(E_{12}\right)$. The uncertainty in the ply major Poisson's ratio $\left(\nu_{112}\right)$ results mainly from the uncertainties in the fiber and matrix Poisson's ratios and the fiber volume ratio as shown in Figure 5. The probabilistic tensile strength in the fiber direction $\left(S_{111 T}\right)$ was simulated and shown in Figure 6. From the simulation, the probabilistic tensile strength is most sensitive to the uncertainties in the fiber tensile strength and fiber volume ratio.

The cumulative distribution functions (cdf) of the equivalent laminate moduli and their sensitivities to the random variables are shown in Figures 7 to 9 . It is found that both the modulus in the $\mathrm{X}$ direction $\left(\mathrm{E}_{\mathrm{tx}}\right)$ and the in-plane shear modulus $\left(\mathrm{E}_{\mathrm{cxy}}\right)$ are sensitive to the uncertain fiber modulus and fiber volume ratio as shown in Figures 7 and 8. In Figure 9 , the uncertainty in the equivalent major Poisson's ratio $\left(\nu_{\text {cxy }}\right)$ results from the uncertainties in fiber modulus, fiber volume ratio, fiber and matrix Poisson ratios, matrix shear modulus and ply misalignment. Based on the strengths calculated in the ply level, the laminate tensile strength in the $\mathrm{X}$ direction $\left(\mathrm{S}_{\mathrm{exx} \mathrm{T}}\right)$ was predicted by assumed both first ply failure and fiber fracture failure modes as shown in Figure 10. It is shown that neither scatter predicted by these two criteria covers the experimental scatter. However, the experimental scatter falls between the scatter domain predicted by both failure criteria. Indeed, the assumed failure modes represent extreme "failure" sceneries in a composite specimen. Consequently, the predicted cdf's describe upper and lower bounds of the laminate strength. From the sensitivity analysis, the tensile strength predicted by first ply failure mode is most sensitive to the fiber modulus and matrix tensile strength. On the other hand, the tensile strength predicted by fiber fracture mode is most sensitive to fiber tensile strength and fiber volume ratio.

\section{CONCLUDING REMARKS}

A methodology has been developed to accurately and efficiently simulate the uncertainties in composite material properties at all scales of the composite considering the uncertainties in all variables describing the composite material behavior (constituent material properties and fabrication variables). This methodology, integrating the probabilistic concepts in conjunction with composite mechanics, has been implemented into the computer code PICAN.

The accuracy and efficiency of the present methodology were demonstrated by comparison with the Monte Carlo simulation method. The uncertainties in ply and laminate properties were quantified. The experimental data of the composite material properties at 
all scales fall within the scatters predicted by PICAN. The sensitivity of the material property to each random variable at the constituent and ply levels was computed. This information can be used as a guide to increase the structural reliability or to reduce the cost. Furthermore, the probabilistic structural analysis and risk assessment can be performed once the uncertain ply and laminate properties are computationally simulated. It is also interesting to note that the most sensitive random variables for the laminate strengths predicted by different failure mode may be different.

\section{REFERENCES}

1. Stock, T.A., P.X. Bellini, P.L.N. Murthy, and C.C. Chamis, 1988. "A Probabilistic Approach to Composite Micromechanics." NASA TM 101366.

2. Chamis, C.C. and Stock, T.A., 1990. "Probabilistic Simulation of Uncertainties in Composite Uniaxial Strengths." NASA TM 102483.

3. Mase, G.T., P.L.N. Murthy, and C.C. Chamis, 1991. "Probabilistic Micromechanics and Marcomechanics of Polymer Matrix Composites." NASA TM 103669.

4. Shiao, M.C. and C.C. Chamis, 1991. "Probabilistic Evaluation of Fuselage-Type Composite Structures." NASA TM 105881.

5. Murthy, P.L.N. and C.C. Chamis, 1986. "Integrated Composite Analyzer (ICAN), Users and Programmers Manual." NASA TP 2515.

6. Wu, Y.T., 1985. "Demonstration of a New, Fast Probability Integration Method for Reliability Analysis," in Advances in Aerospace Structural Analysis, O.H. Burnside and C.H. Parr, ed., ASME, New York, pp. 63-73.

7. Chamis, C.C., R.F. Lark, and J.H. Sinclair, 1978. "Integrated Theory for Predicting the Hygrothermomechanical Response of Advanced Composite Structural Components, " ASTM STP-658, pp. 160-192. 
TABLE 1- STATISTICAL PROPERTIES OF RANDOM VARIABLES

\begin{tabular}{|c|c|c|c|c|}
\hline Random Variables & Ref. [4] & $\begin{array}{l}\text { Mean } \\
\text { Value }\end{array}$ & $\begin{array}{c}\text { cov (or } \\
\text { stdv) }\end{array}$ & $\begin{array}{c}\text { Distribution } \\
\text { Type }\end{array}$ \\
\hline 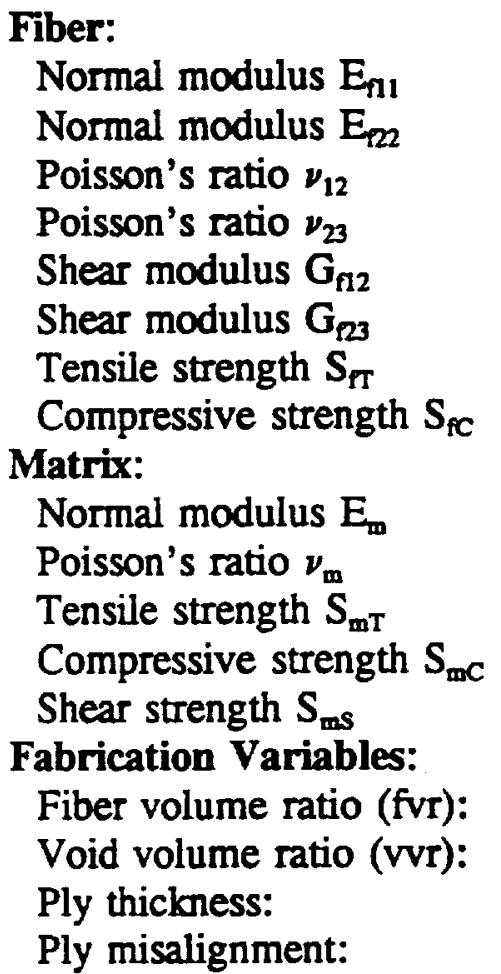 & $\begin{array}{c}32 \mathrm{mpsi} \\
2 \mathrm{mpsi} \\
0.2 \\
0.2 \\
2 \mathrm{mpsi} \\
2 \mathrm{mpsi} \\
400 \mathrm{ksi} \\
400 \mathrm{ksi} \\
\\
0.4 \mathrm{mpsi} \\
0.4 \\
7 \mathrm{ksi} \\
36.3 \mathrm{ksi} \\
7 \mathrm{ksi} \\
\\
60 \% \\
0.01 \% \\
0.0055 \mathrm{in} . \\
0\end{array}$ & $\begin{array}{c}32 \mathrm{mpsi} \\
3 \mathrm{mpsi} \\
0.23 \\
0.25 \\
2.5 \mathrm{mpsi} \\
2.5 \mathrm{mpsi} \\
400 \mathrm{ksi} \\
400 \mathrm{ksi} \\
\\
0.45 \mathrm{mpsi} \\
0.41 \\
6.7 \mathrm{ksi} \\
39 \mathrm{ksi} \\
8.9 \mathrm{ksi} \\
\\
60 \% \\
0.01 \% \\
0.0055 \mathrm{in} . \\
0\end{array}$ & $\begin{array}{l}8 \% \\
8 \% \\
8 \% \\
8 \% \\
8 \% \\
8 \% \\
8 \% \\
8 \% \\
\\
8 \% \\
8 \% \\
8 \% \\
8 \% \\
8 \%\end{array}$ & $\begin{array}{l}\text { Normal } \\
\text { Normal } \\
\text { Normal } \\
\text { Normal } \\
\text { Normal } \\
\text { Normal } \\
\text { Weibull } \\
\text { Weibull } \\
\\
\text { Normal } \\
\text { Normal } \\
\text { Weibull } \\
\text { Weibull } \\
\text { Weibull }\end{array}$ \\
\hline
\end{tabular}




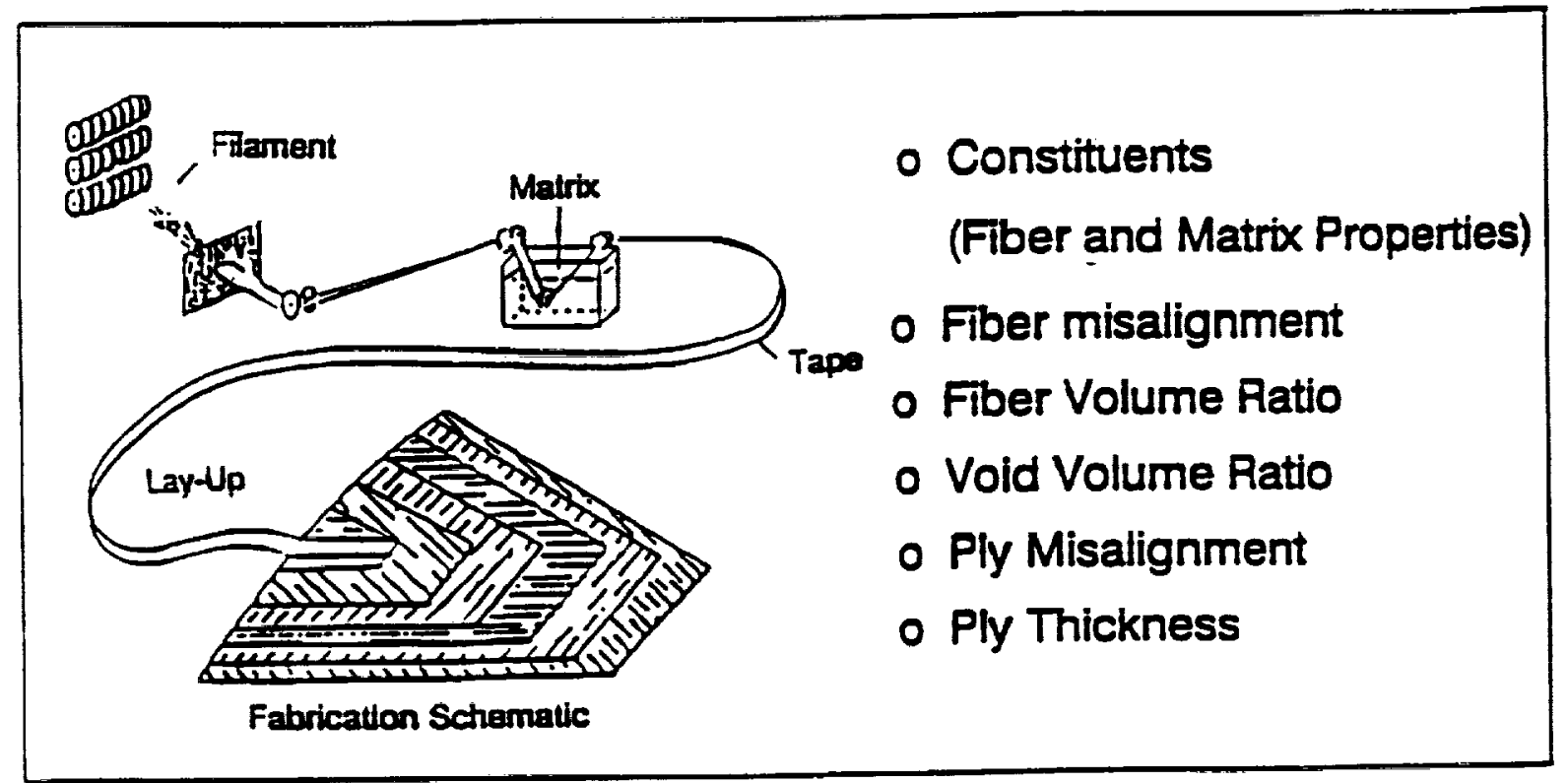

Figure 1. Random Variables in the Typical Fabrication Process

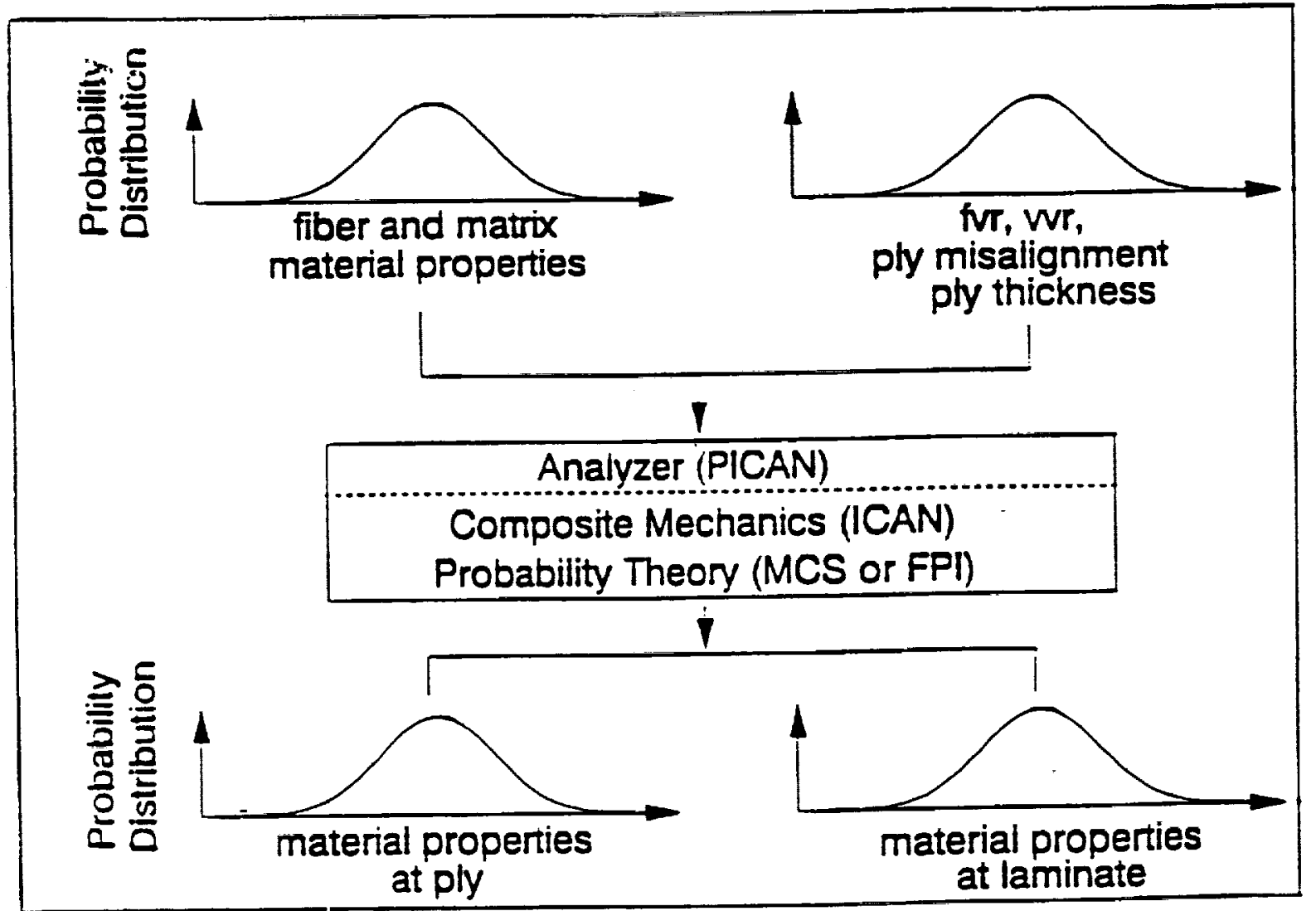

Figure 2. Probabilistic Simulation of Composite Materials 


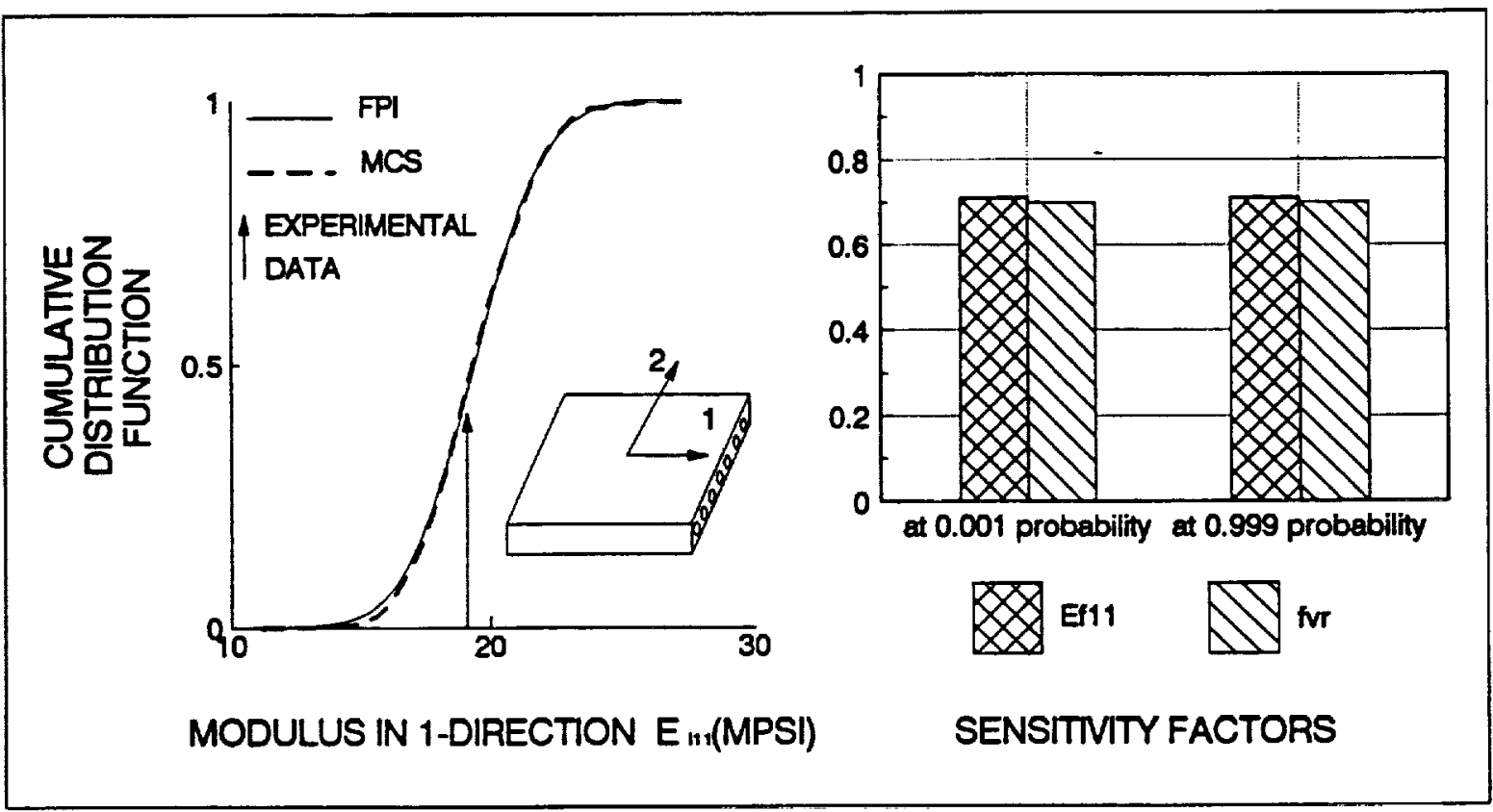

Figure 3. CDF's and Sensitivity Factors of Ply Modulus in X-Direction

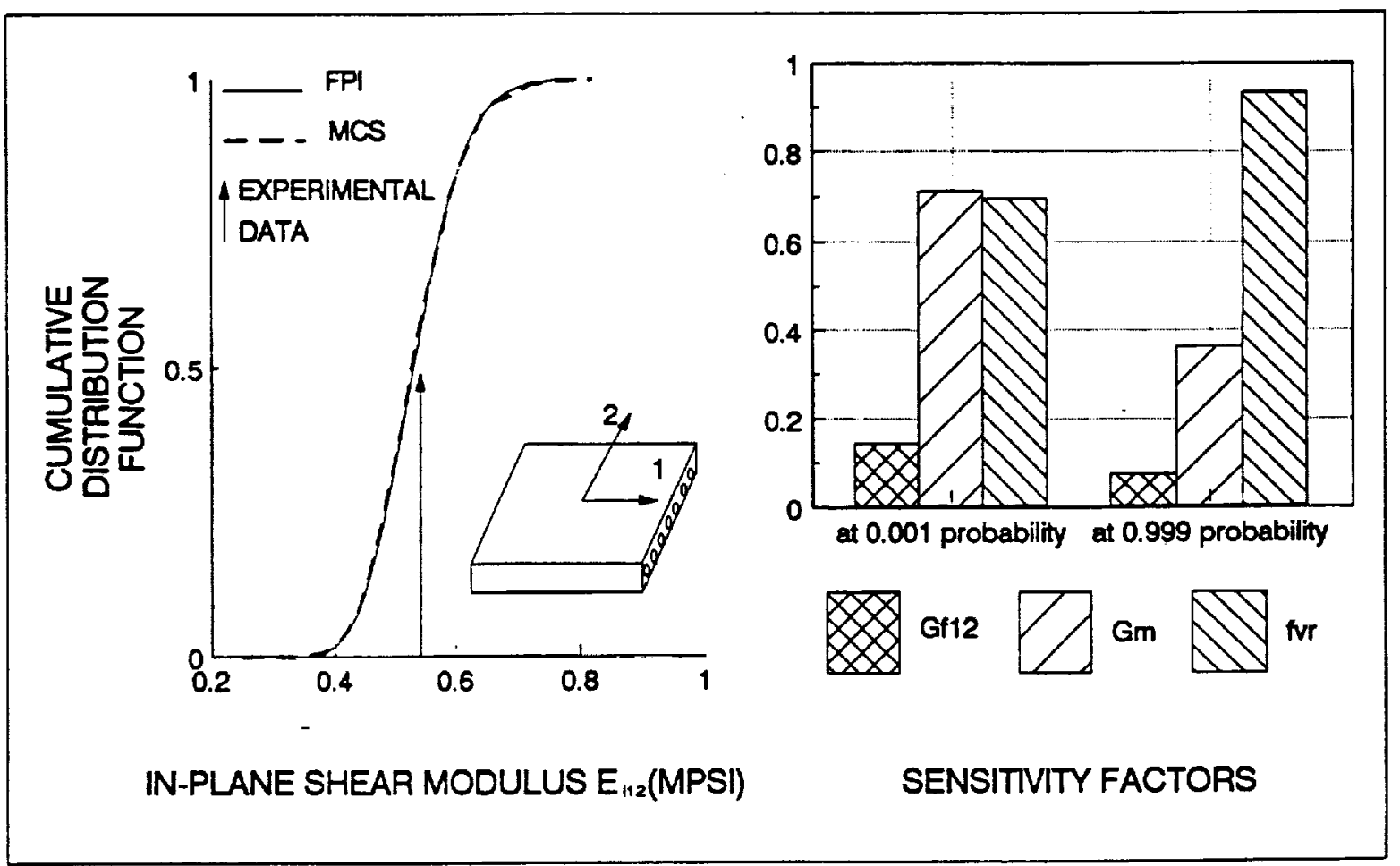

Figure 4. CDF's and Sensitivity Factors of Ply In-Plane Shear Modulus 


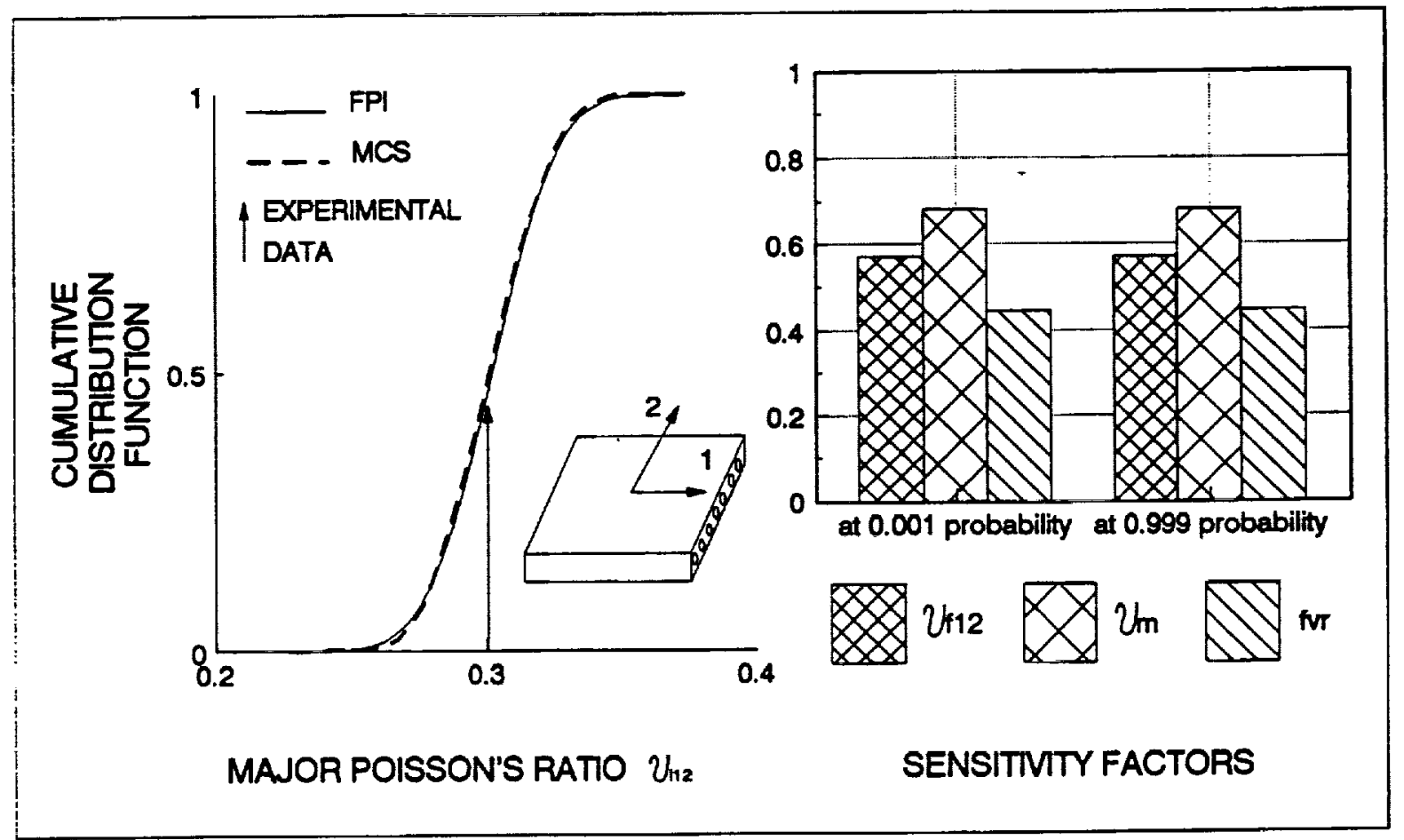

Figure 5. CDF's and Sensitivity Factors of Ply Major Poisson's Ratio

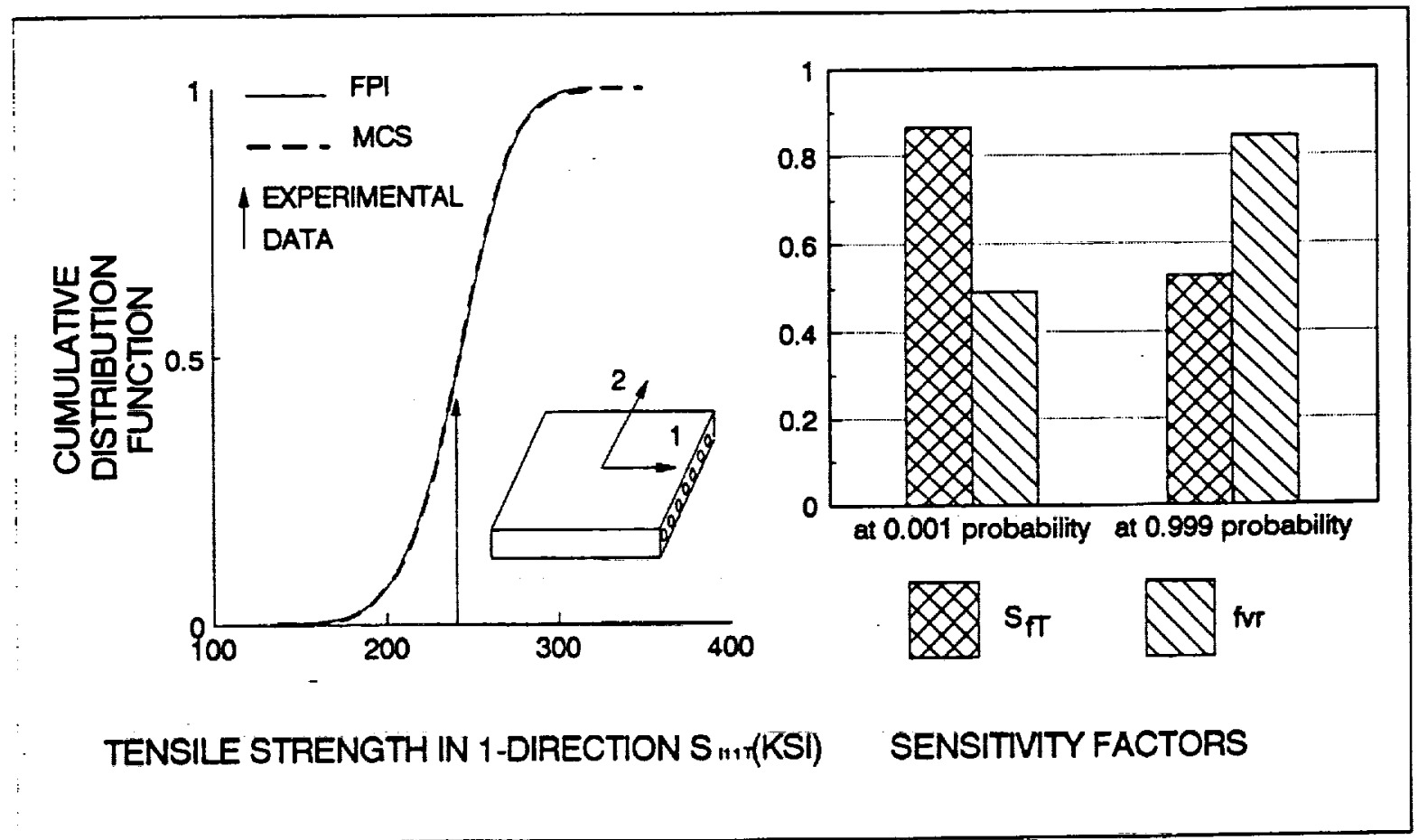

Figure 6. CDF's and Sensitivity Factors of Ply Tensile Strength in X-Direction 


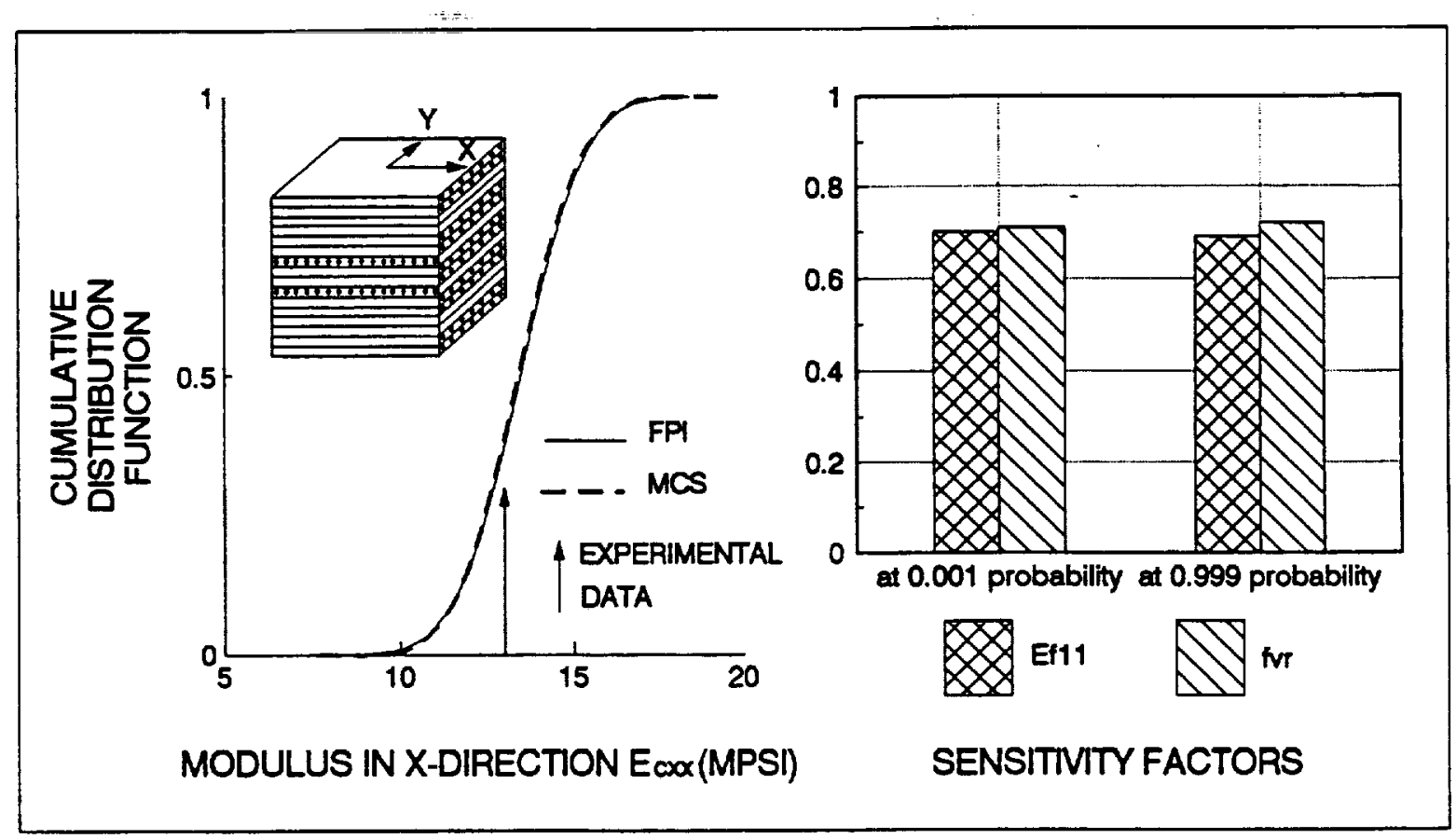

Figure 7. CDF's and Sensitivity Factors of Laminate Modulus in X-Direction

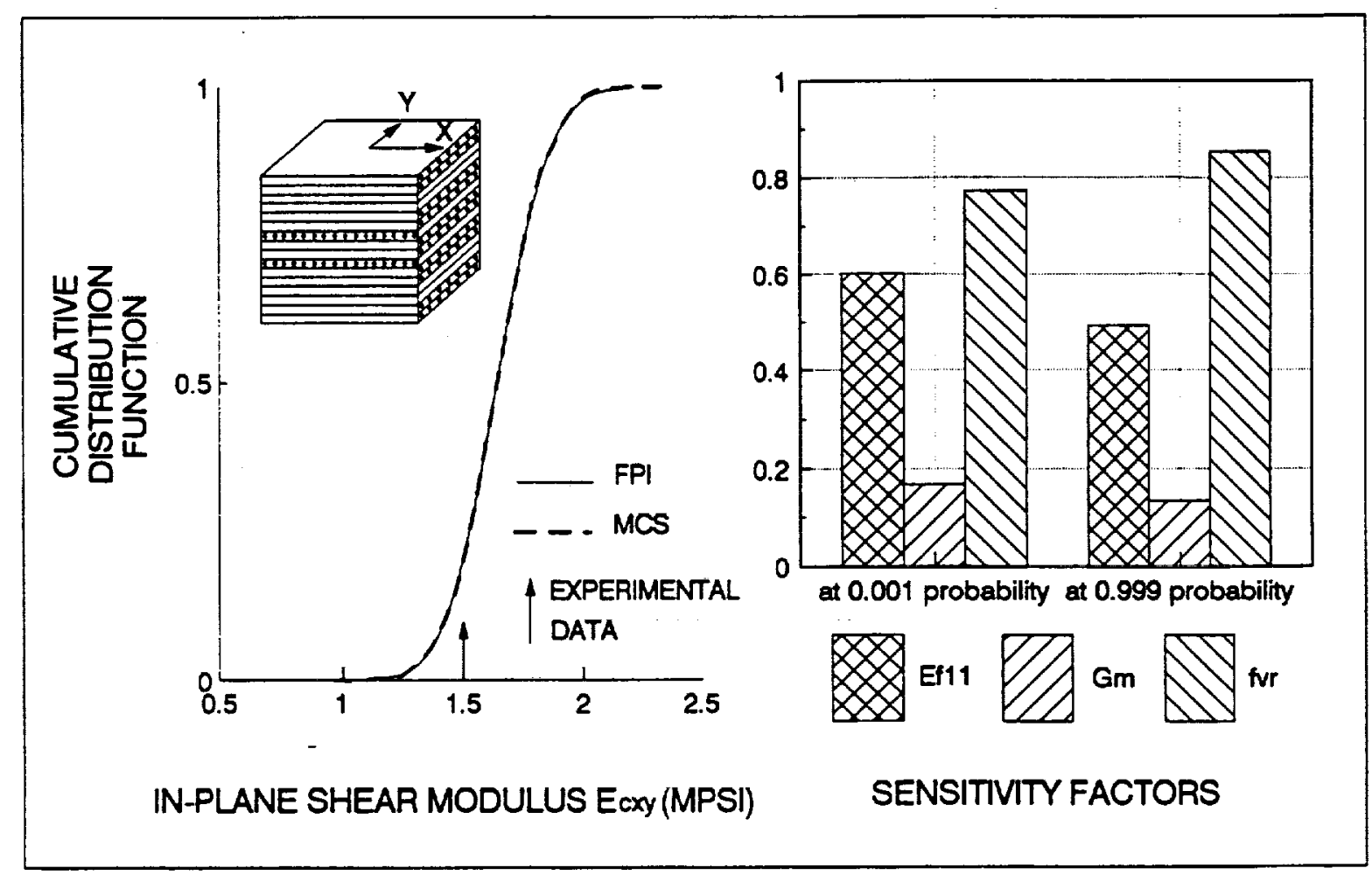

Figure 8. CDF's and Sensitivity Factors of Laminate In-Plane Shear Modulus 


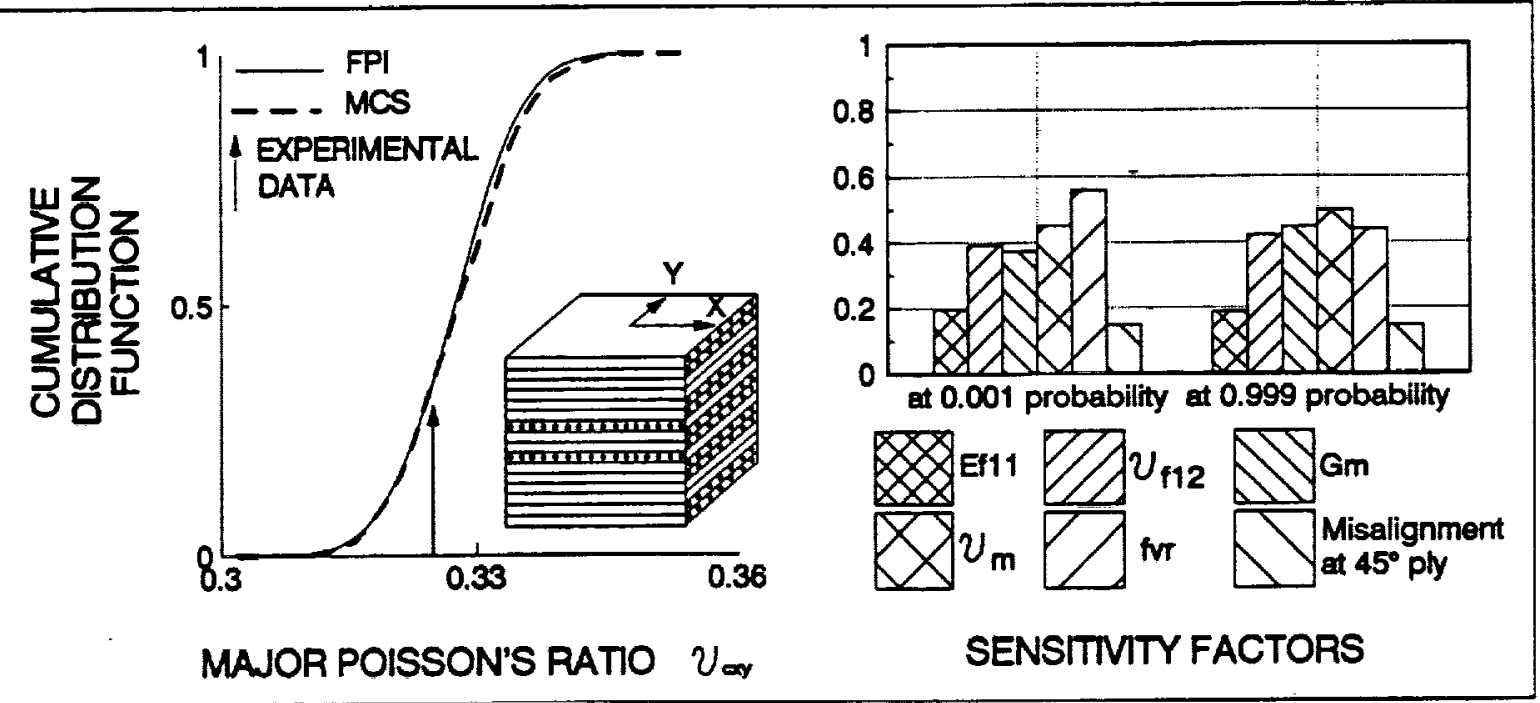

Figure 9. CDF's and Sensitivity Factors of Laminate Major Poisson's Ratio

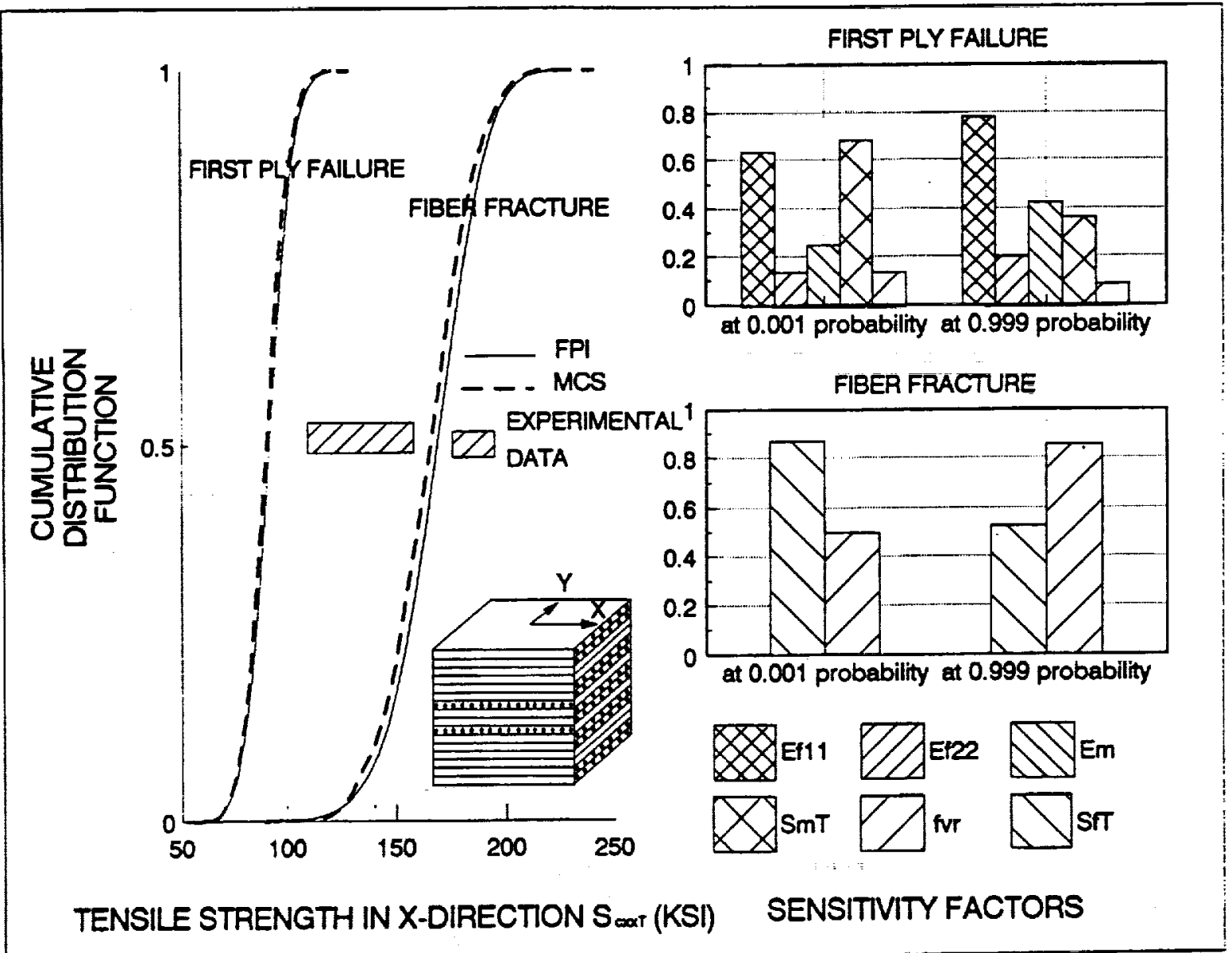

Figure 10. CDF's and Sensitivity Factors of Laminate Tensile Strength in $X$-Direction 



\section{REPORT DOCUMENTATION PAGE}

Public reporting burden for this collection of information is estimated to average 1 hour per response, including the time for reviewing Instructions, searching existing data sources, Pethering and completing and reviewing the collection of information. Send comments regarding this burden estimate or amy other aspect of this gathering and mairtaining tho data noeded, and collection of hiormation,

\begin{tabular}{|l|l|l|l} 
1. AGENCY USE OKLY (Loave blank) & 2. REPOAT DATE & 3. REPORT TYPE AND DATES COVERED
\end{tabular}

June 1993

Technical Memorandum

\section{TILE AND SUBTILE}

5. FUNDWG NUMBERS

Probabilistic Simulation of Multi-Scale Composite Behavior

6. AUTHOR(S)

D.G.Liaw, M.C. Shiao, S.N. Singhal, and C. Chamis

- WU-510-02-12

7. PERforming ORganization name(S) AND ADDRESS(ES)

National Aeronautics and Space Administration

Lewis Research Center

Cleveland, Ohio 44135-3191

Q. PERFORMING ORGANIZATION REPOAT NUMBER

E-7904

9. SPONSORINGNONTORING AGENCY NAME(S) AND ADDRESS(ES)

10. SPONSORINGMONTTORING AGENCY REPORT NUMBER

National Aeronautics and Space Administration

Washington, D.C. 20546-0001

NASA TM-106196

11. SUPPLEMENTARY NOTES

Prepared for the Sixth Japan-United States Conference on Composite Materials, Orlando, Florida, June 22-25, 1992. D.G. Liaw, M.C. Shiao, and S.N. Singhal, Sverdrup Technology, Inc. Lewis Research Center Group, 2001 Aerospace Parkway, Brook Park, Ohio 44142 and C. Chamis, NASA Lewis Research Center, Cleveland, Ohio. Responsible person, C. Chamis, (216) 433-3252.

12. DISTRIBUTION/AVAILABILTY STATEMENT

12b. DISTRIBUTION CODE

Unclassified - Unlimited

Subject Category 39

13. ABSTRACT (Thex/mum 200 words)

A methodology is developed to computationally assess the probabilistic composite material properties at all composite scale levels due to the uncertainties in the constituent (fiber and matrix) properties and in the fabrication process variables. The methodology is computationally efficient for simulating the probability distributions of material properties. The sensitivity of the probabilistic composite material property to each random variable is determined. This information can be used to reduce undesirable uncertainties in material properties at the macro scale of the composite by reducing the uncertainties in the most influential random variables at the micro scale. This methodology has been implemented into the computer code PICAN (Probabilistic Integrated Composite ANalyzer). The accuracy and efficiency of this methodology are demonstrated by simulating the uncertainties in the material properties of a typical laminate and comparing the results with the Monte Carlo simulation method. The experimental data of composite material properties at all scales fall within the scatters predicted by PICAN.

14. SUBJECT TERUS

Probability; Composite; Uncertainty; Scatter; Sensitivity; Laminate; Constituent

15. NUMBER OF PAGES

14

\begin{tabular}{|c|c|c|}
\hline $\begin{array}{l}\text { 17. SECURTY CLASSIFICATION } \\
\text { OF REPOAT } \\
\text { Unclassified }\end{array}$ & $\begin{array}{l}\text { 18. SECURTY CLASSIFICATION } \\
\text { OF THIS PAGE } \\
\text { - Unclassified }\end{array}$ & $\begin{array}{l}\text { 19. SECURTY CLASSIFICATION } \\
\text { OF ABSTRACT } \\
\text { Unclassified }\end{array}$ \\
\hline
\end{tabular}

16. PAICE CODE

A03 